\title{
Determination of Etiology for Exercise-Induced Dyspnea
}

\author{
Mutasim Abu-Hasan ${ }^{1}$, Rajeev Bhatia ${ }^{2}$, and Miles Weinberger ${ }^{3}$ \\ ${ }^{1}$ University of Florida \\ ${ }^{2}$ Phoenix Children's Hospital \\ ${ }^{3}$ University of California San Diego
}

March 8, 2021

\begin{abstract}
Two recent publications in Pediatric Pulmonology had methodological limitations in evaluating exercise-induced dyspnea (EID). Testing that does not include concurrence of dyspnea with an abnormality may provide misleading information to the detriment of the patient. Reproducing the patient's dyspnea during cardiopulmonary monitoring provides the etiology of at least 7 causes of EID, many of which may not otherwise be identified.
\end{abstract}

\section{Hosted file}

Letter to Ped Pulm.pdf available at https://authorea.com/users/391725/articles/512607determination-of-etiology-for-exercise-induced-dyspnea 